\title{
Structures, sorption characteristics and nonlinear optical properties of a new series of highly stable aluminium MOFs
}

\author{
Helge Reinsch ${ }^{\dagger}$, Monique Van der Veen ${ }^{\ddagger},{ }^{*}$, Barbara Gil ${ }^{\diamond}$, Bartosz Marszalek ${ }^{\diamond}$, Thierry Verbiest ${ }^{\S}$, Dirk \\ de $\operatorname{Vos}^{\ddagger}$, Norbert Stock ${ }^{\dagger *}$ \\ ${ }^{\dagger}$ Institut für Anorganische Chemie, Christian-Albrechts-Universität zu Kiel, Max-Eyth-Straße 2, 24118 Kiel (Germany). \\ ¥Centre for Surface Chemistry and Catalysis, University of Leuven, Kasteekpark Arenberg 23, 3001 Leuven (Belgium) \\ ${ }^{\S}$ Molecular Electronics and Photonics, University of Leuven, Celestijnenlaan 200D, 3001 Leuven (Belgium). ${ }^{\diamond}$ Faculty of \\ Chemistry, Jagiellonian University, ul. Ingardena 3, 30-060 Kraków, (Poland).
}

\begin{abstract}
KEYWORDS metal-organic frameworks; aluminium carboxylates; porous materials; nonlinear optical properties; isoreticular chemistry
\end{abstract}

Supporting Information Placeholder

\begin{abstract}
Employing high-throughput methods, the synthesis conditions for a series of six new MOFs based on aluminium ions and the V-shaped linker molecule 1,3-benzene dicarboxylic acid, denoted as CAU-10-X (CAU = Christian-Albrechts-University) with the sum formula $\left[\mathrm{Al}(\mathrm{OH})\left(\mathrm{C}_{8} \mathrm{H}_{3} \mathrm{O}_{4} \mathrm{X}\right)\right]$-solvent, were established $(\mathrm{X}=$ functional group in 5-position of the aromatic ring; $\mathrm{X}=$ $\mathrm{H}(\mathbf{1}), \mathrm{CH}_{3}(\mathbf{2}), \mathrm{OCH}_{3}(\mathbf{3}) \mathrm{NO}_{2}(\mathbf{4}), \mathrm{NH}_{2}(\mathbf{5})$, or $\left.\mathrm{OH}(\mathbf{6})\right)$. Due to the absence of macroscopic crystals, the obtained compounds were structurally characterized employing XRPD-methods. The crystal structures of 1, 2 and 3 were refined using Rietveld methods. Although the described MOFs are isoreticular, they crystallize in several, sometimes non-centrosymmetric space groups $(\mathbf{1}, \mathbf{4}, \mathbf{6})$, due to slight structural changes induced by the functionalization. These space groups were confirmed with second-harmonic generation measurements. All compounds are highly stable as confirmed by temperature-dependent XRPD- and IR-experiments and decompose at temperatures above $350{ }^{\circ} \mathrm{C}$. The stabilities of all compounds in aqueous solutions of varying $\mathrm{pH}$ were confirmed by XRPD-measurements and their sorption properties towards nitrogen, hydrogen, carbon dioxide and water vapor at low pressures are reported. A drastic influence of the functional group on affinity, capacity and accessibility of the pores for these gases is observed. These properties depend on the polarity and size of the functional group as well as on subtle structural differences between the CAU-10-X compounds.
\end{abstract}

\section{Introduction}

Metal-organic frameworks are often objected to as potential materials for a variety of applications like gas storage, separation processes, as sensor materials or in pharmaceutical applications..$^{[1,2,3,4]}$ Their main advantage is the modular building principle rooted in the assembly of separate organic and inorganic building units. This allows in theory the facile tuning of their properties, either by the chemical functionalization of the organic building units or by replacement of the inorganic units. This approach is known as isoreticular chemistry, which is supposed to result in "tailored" properties, suitable to the application of interest. ${ }^{[5]}$ This principle has shown to be valuable for a small number of compounds, while the majority of structures remains unique. Prominent examples of the successful isoreticular synthesis are most often based on linear aromatic dicarboxylate ions, which are varied in size and by additional functional groups. ${ }^{[6,7]}$ This is most probably due to the commercial availability of a rather large number of linker molecules exhibiting this linear geometry. As an example, a large number of compounds based on the MIL-53-topology are known and well characterized (MIL stands for Matériaux d'Institute Lavoisier). The inorganic unit in this type of framework is a chain of transconnected $\mathrm{M}(\mathrm{III}) \mathrm{O}_{6}$-polyhedra, which are connected by linear dicarboxylate ions. ${ }^{[8]}$ The size of these dicarboxylate ions can be varied in a wide range, thus the smallest linker incorporated until now is the fumarate ion (trans-1,2ethylenedicarboxylate). ${ }^{[9]}$ The largest molecule used for the synthesis of the MIL-53-topology is the 4,4'biphenyldicarboxylic acid. ${ }^{[10]}$ Furthermore, a manifold of compounds based on functionalized 1,4-benzenedicarboxylic acid can be synthesized. ${ }^{[11,12]}$ The diversity of this topology is increased due to the large number of cations that can act as inorganic unit, like $\mathrm{Al}^{3+[8]}, \mathrm{Sc}^{3+[13]}, \mathrm{Fe}^{3+[14]}, \mathrm{Cr}^{3+[15]}, \mathrm{In}^{3+16}$ or $\mathrm{Ga}^{3+[17]}$. Among these compounds, especially the MOFs based on aluminium and chromium have shown to be chemically and thermally stable. ${ }^{[1819]}$ Moreover, the low price and the low toxicity of aluminium salts have resulted in a profound interest of industrial research groups in these materials. ${ }^{[9]}$ These are the reasons for our interest in the synthesis of new MOFs based on aluminium. While a large number of compounds based on the MIL-53-topology can be readily synthesized, there is no example for MOFs based on aluminium and the $\mathrm{V}$-shaped 1,3-benzene dicarboxylic acid (isophtalic acid or $1,3-\mathrm{H}_{2} \mathrm{BDC}$ ). To the best of our knowledge there is no example at all for a porous compound based on this linker molecule and one of the mentioned trivalent cations, although the isophthalic acid is non-toxic and available at low cost. This is very surprising since a variety of modi- 
fied isophthalic acids are commercially available, which in principle eases the synthesis of isoreticular MOFs.

Therefore, we started a systematic investigation of the solvothermal system $\mathrm{Al}^{3+}$ / isophthalic acid / solvent. For this investigation, we took also the requirements of industrial research into account, i.e. the preferable use of $\mathrm{Al}_{2}\left(\mathrm{SO}_{4}\right)_{3} \cdot 18 \mathrm{H}_{2} \mathrm{O}$, a low amount of organic solvents and rather mild synthesis conditions. ${ }^{[9]}$ By applying highthroughput (HT-) methods, ${ }^{[20,21]}$ we discovered a new porous aluminum isophthalate, denoted as CAU-10-H with the sum formula $[\mathrm{Al}(\mathrm{OH})(1,3-\mathrm{BDC})]$. Using the reaction conditions for the synthesis of CAU-10-H as a starting point, the HTmethods were further employed to optimize the synthesis conditions for five other members of this series bearing $\mathrm{NO}_{2}-$ , $\mathrm{NH}_{2-}, \mathrm{CH}_{3^{-}}, \mathrm{OCH}_{3^{-}}$or $\mathrm{OH}$-groups. For a detailed characterization of all members of the CAU-10-series sorption experiments were carried out with $\mathrm{N}_{2}$ and $\mathrm{H}_{2}$ at $77 \mathrm{~K}$ and with $\mathrm{CO}_{2}$ and $\mathrm{H}_{2} \mathrm{O}$ at $298 \mathrm{~K}$. In addition, thermogravimetric experiments as well as temperature dependent XRPD- and IRmeasurements were performed and stability tests in a wide $\mathrm{pH}$-range were carried out. To identify structural transitions and to confirm the chirality and polarity of some of these MOFs, the CAU-10-series was further characterized by means of SHG-measurements.

\section{Experimental Section}

Materials and Methods. All chemicals are commercially available and were employed without further purification. A detailed description of our HT-methods is given elsewhere. [22] The HT-studies for the discovery and optimisation of CAU-10-H are described in the supporting information. For the upscaled reactions, custom made teflon-reactors in steel autoclaves with a volume of $37 \mathrm{~mL}$ or glass reactors for solvothermal conditions with a volume of $100 \mathrm{~mL}$ were employed. The initial characterization by means of XRPDmethods was carried out on a STOE-Stadi-P diffracometer $\left(\mathrm{Cu} \mathrm{K} \mathrm{K}_{\alpha 1}\right.$-radiation) equipped with a xy-stage and an imageplate-detector. The data for the structure solution and refinement was collected on a STOE-Stadi-P diffractometer ( $\mathrm{Cu} \mathrm{K} \mathrm{K}_{\alpha 1}$-radiation) equipped with a PSD-detector. The synchrotron-XRPD data for the refinement of CAU-10-H was measured at the beamline P8 of the PETRA-accelerator ring at the DESY in Hamburg. The wavelength was set to 0.495 $\AA$ and the pattern was recorded on a $2 \mathrm{D}$-CCD-detector. The raw data was converted with the fit2D-program. ${ }^{[23]}$ The suitability of this setup was confirmed by the successful refinement of the NIST-standard $\mathrm{CeO}_{2}$ and the Al-based MOF CAU-1-NH ${ }_{2}{ }^{24}$ Temperature dependent XRPD-data was measured in capillaries on a STOE-Stadi-P diffractometer equipped with an image plate detector using $\mathrm{Cu} \mathrm{\textrm {K } _ { \alpha 1 ^ { - } }}$ radiation. The software used for the structure determination was Expo2009, ${ }^{[25]}$ the refinements were performed with TOPAS. ${ }^{[26]}$ The software used for force-field-calculations, to complete structural fragments and to optimize some of the structures by forcefield-calculations was Materials Studio 5.0. ${ }^{[27]}$ IR-spectra measured ambient conditions were measured with a Bruker ALPHA-FT-IR A220/D-01 spectrometer equipped with an ATR-unit. The Raman-spectra were measured with a Bruker IFS 66 FRA 106 spectrometer in the range of $0-3300 \mathrm{~cm}^{-1}$ using a Nd/YAG-Laser (1064 nm). NMR-spectra in solution were measured on a Bruker DRX 500 spectrometer. Solid-state CP-MAS-NMR spectra were recorded on a Bruker DSX Avance 400 FT NMR spectrometer in a $7 \mathrm{~mm} \mathrm{ZrO}_{2}$-rotor at a rotation frequency of $5 \mathrm{kHz}$. Thermogravimetric measurements were performed on a NETZSCH STA 409 CD analyzer under a flow of air with a heating rate of $4 \mathrm{~K} / \mathrm{min}$ in $\mathrm{Al}_{2} \mathrm{O}_{3}$-crucibles. The data was corrected for buoyancy and current effects. EDXmeasurements were performed with a Phillips ESEM XL-30. SEM-micrographs were recorded with a Zeiss Gemini Ultra Plus. Sorption experiments were carried out with a BEL JAPAN INC. Belsorp ${ }_{\max }$. Temperature dependent IR-spectra were recorded with a Bruker Tensor 27 spectrometer equipped with an MCT detector and working with the spectral resolution of $2 \mathrm{~cm}^{-1}$. All presented spectra, except the ones at RT, were measured at $50{ }^{\circ} \mathrm{C}$. For the IR experiment a silicon wafer was covered by a thin layer of the material by evaporating on its surface a few drops of the corresponding dispersion in methanol.

In the SHG microscope the sample is illuminated wide-field under normal incidence with femtosecond pulsed infrared (IR) laser light at $800 \mathrm{~nm}$ (Spectra Physics, Tsunami $\left.{ }^{\circledR}\right)$. The polarization of the incident IR light is varied by a zero-order half-wave plate for $800 \mathrm{~nm}$. The sample is irradiated by a long focal length lens $(\mathrm{f}=7.5 \mathrm{~cm})$, so that the incident fundamental light can be considered in good approximation as a collimated beam, and electric field components along the propagation direction $(\mathrm{Z})$ can be neglected. Behind the sample, a high-power objective (Thorlabs, LMU-15X-NUV) collimates the transmitted light. An interference filter (Melles-Griot, FWHM) centered at $400 \mathrm{~nm}$ selectively transmits the second-harmonic light. A Glan-Taylor polarizer can be inserted as analyzer. Finally, an EM-CCD camera (C9100, Hamamatsu) collects the transmitted light.

Synthesis. CAU-10-H (1) was synthesized from a mixture of $200 \mathrm{mg} \quad 1,3-\mathrm{H}_{2} \mathrm{BDC} \quad(1.20 \mathrm{mmol}), 800 \mathrm{mg}$ of $\mathrm{Al}_{2}\left(\mathrm{SO}_{4}\right)_{3} \cdot 18 \mathrm{H}_{2} \mathrm{O}(1.20 \mathrm{mmol}), 1 \mathrm{~mL} \mathrm{~N}, \mathrm{~N}$-dimethylformamid (DMF) and $4 \mathrm{~mL} \mathrm{H}_{2} \mathrm{O}$. The reactants were dosed into a teflon-lined steel-autoclave with a volume of $37 \mathrm{~mL}$ and placed in an oven for $12 \mathrm{~h}$ at $135^{\circ} \mathrm{C}$. After cooling to room temperature, the product was filtered off and the obtained solid was redispersed in water by sonication and stirring, until a homogenous mixture was obtained. The dispersion was filtered again and the white microcrystalline solid was dried in air. Elemental analysis: C $40.2 \%, \mathrm{H} 4.6 \%$. Calculated values based on the deduced sum formula $\left[\mathrm{Al}(\mathrm{OH})\left(\mathrm{O}_{2} \mathrm{C}-\mathrm{C}_{6} \mathrm{H}_{4}\right.\right.$ $\left.\left.\mathrm{CO}_{2}\right)\right] \cdot 1.7 \mathrm{H}_{2} \mathrm{O}: \mathrm{C} 40.2 \%, \mathrm{H} 3.1 \%$. This synthesis procedure is also applicable in larger teflon reactors with a comparably low filling degree (15 to $20 \%$ ), while in glass reactors the formation of an unknown crystalline byproduct was observed.

The methylated MOF CAU-10- $\mathrm{CH}_{3}$ (2) was synthesized in a $100 \mathrm{~mL}$ glass reactor with screw cap. Therefore $0.80 \mathrm{~g}(4.44$ mmol) 5-methylisophthalic acid, $2.96 \mathrm{~g} \quad \mathrm{Al}_{2}\left(\mathrm{SO}_{4}\right)_{3} \cdot 18 \mathrm{H}_{2} \mathrm{O}$ (4.44 mmol), $4 \mathrm{~mL}$ DMF and $16 \mathrm{~mL} \mathrm{H}_{2} \mathrm{O}$ were mixed thoroughly and heated for $12 \mathrm{~h}$ to $130{ }^{\circ} \mathrm{C}$. After cooling to room temperature, the filtered product was redispersed in $\sim 200$ $\mathrm{mL}$ water by sonication and stirring. Afterwards, the mixture was filtered again and the pale yellow solid was dried under 
ambient conditions. Elemental analysis: C 46.1\%, H $4.1 \%$, $\mathrm{N} 1.4 \%$. Calculated values based on the deduced sum formula $\left[\mathrm{Al}(\mathrm{OH})\left(\mathrm{O}_{2} \mathrm{C}-\mathrm{C}_{6} \mathrm{H}_{4} \mathrm{OCH}_{3}-\mathrm{CO}_{2}\right)\right] \cdot 0.73 \mathrm{H}_{2} \mathrm{O} \cdot 0.25 \mathrm{DMF}$ : $\mathrm{C} 46.1 \%, \mathrm{H} 4.1, \mathrm{~N} 1.4 \%$. The synthesis in teflon-lined autoclaves results in the formation of the same reaction product, but DMF-molecules are occluded inside the pores of this product, which could not be removed by heating or evacuation.

The $\mathrm{OCH}_{3}$-functionalized MOF CAU-10- $\mathrm{OCH}_{3}$ (3) was also synthesized in a $100 \mathrm{~mL}$ glass reactor with screw cap. $1.20 \mathrm{~g}$ (6.12 mmol) 5-methoxyisophthalic acid, $2.04 \mathrm{~g}$ $\mathrm{Al}_{2}\left(\mathrm{SO}_{4}\right)_{3} \cdot 18 \mathrm{H}_{2} \mathrm{O}(4.44 \mathrm{mmol}), 3 \mathrm{~mL} \mathrm{DMF}$ and $12 \mathrm{~mL} \mathrm{H} \mathrm{H}_{2} \mathrm{O}$ were mixed thoroughly and heated for $12 \mathrm{~h}$ at $130{ }^{\circ} \mathrm{C}$. After cooling to room temperature, the white microcrystalline product was processed in the same way as CAU-10- $\mathrm{CH}_{3}$. Elemental analysis: C $44.9 \%, \mathrm{H} 3.6 \%$, N $1.2 \%$. Calculated values based on the deduced sum formula $\left[\mathrm{Al}(\mathrm{OH})\left(\mathrm{O}_{2} \mathrm{C}\right.\right.$ $\left.\left.\mathrm{C}_{6} \mathrm{H}_{4} \mathrm{OCH}_{3}-\mathrm{CO}_{2}\right)\right] \cdot 1.3 \mathrm{H}_{2} \mathrm{O} \cdot 0.24$ DMF: $\mathrm{C} 42.9 \%$, H 4.1, N $1.2 \%$.

For the other three compounds, we had to develop a different synthesis route, since the stronger polarity of the $\mathrm{NO}_{2-}$, the $\mathrm{NH}_{2-}$ and the $\mathrm{OH}$-group led to the occlusion of sulfate ions inside the channels of the MOF, as measured by EDXanalysis.

The $\mathrm{NO}_{2}$-functionalized CAU-10- $\mathrm{NO}_{2}$ (4) was synthesized using a $2 \mathrm{M}$ solution of $\mathrm{AlCl}_{3} \cdot 6 \mathrm{H}_{2} \mathrm{O}$ in water as the $\mathrm{Al}^{3+}$ source. Thus, $1440 \mathrm{mg}$ (6.82 mmol) 5-nitroisophthalic acid, $3.4 \mathrm{~mL} \mathrm{Al}^{3+}$-solution $(6.80 \mathrm{mmol}), 4 \mathrm{~mL} \mathrm{DMF}$ and $12.6 \mathrm{~mL}$ $\mathrm{H}_{2} \mathrm{O}$ were filled into a $100 \mathrm{~mL}$ glass reactor with screw cap. The mixture was heated at $120{ }^{\circ} \mathrm{C}$ for $12 \mathrm{~h}$, and the product was worked up in the same way as the other compounds. Elemental analysis: C $38.1 \%, \mathrm{H} 2.5 \%$, N $6.8 \%$. Calculated values based on the deduced sum formula $\left[\mathrm{Al}(\mathrm{OH})\left(\mathrm{O}_{2} \mathrm{C}\right.\right.$ $\left.\left.\mathrm{C}_{6} \mathrm{H}_{4} \mathrm{NO}_{2}-\mathrm{CO}_{2}\right)\right] \cdot 0.41$ DMF: C $39.1 \%, \mathrm{H} 2.4, \mathrm{~N} 7.0 \%$.

The $\mathrm{NH}_{2}$-functionalized CAU-10- $\mathrm{NH}_{2}$ (5) was synthesized by dosing $1200 \mathrm{mg}$ (6.63 mmol) 5-aminoisophthalic acid, $3.3 \mathrm{~mL} \mathrm{Al}^{3+}$-solution $(6.6 \mathrm{mmol}), 4 \mathrm{~mL} \mathrm{DMF}$ and $12.7 \mathrm{~mL}$ $\mathrm{H}_{2} \mathrm{O}$ into a $100 \mathrm{~mL}$ glass reactor with screw cap. The mixture was heated at $120{ }^{\circ} \mathrm{C}$ for $12 \mathrm{~h}$, and the resulting pale pink solid was filtered off. The reaction product was redipersed in water by sonication for 30 minutes, filtered off again and dried for one hour at $200{ }^{\circ} \mathrm{C}$ in air. Elemental analysis: $\mathrm{C}$ $42.8 \%, \mathrm{H} 2.9 \%$, N $6.4 \%$. Calculated values based on the deduced sum formula $\left[\mathrm{Al}(\mathrm{OH})\left(\mathrm{O}_{2} \mathrm{C}-\mathrm{C}_{6} \mathrm{H}_{4} \mathrm{NH}_{2}-\mathrm{CO}_{2}\right)\right]$ : $\mathrm{C} 42.8$ $\%, \mathrm{H} 2.9, \mathrm{~N} 6.4 \%$. Although the analysis matches the chemical formula, $\mathrm{NMR}$-experiments indicate that the $\mathrm{NH}_{2}$-group is partially formylated during the synthesis (see SI, paragraph $\mathrm{XI})$.

The OH-functionalized CAU-10-OH (6) was synthesized by dosing $1000 \mathrm{mg}$ (5.49 mmol) 5-hydroxyisophthalic acid, 2.8 $\mathrm{mL} \mathrm{Al}{ }^{3+}$-solution (5.6 mmol), $4 \mathrm{~mL} \mathrm{DMF}$ and $13.2 \mathrm{~mL} \mathrm{H}_{2} \mathrm{O}$ into a $100 \mathrm{~mL}$ glass reactor with screw cap. The mixture was heated at $120^{\circ} \mathrm{C}$ for $12 \mathrm{~h}$, and the resulting white solid was filtered off. The reaction product was redipersed in water by sonication for 30 minutes, filtered off again and dried for one hour at $200{ }^{\circ} \mathrm{C}$ in air. Elemental analysis: $\mathrm{C} 41.3 \%, \mathrm{H}$ $4.5 \%$. Calculated values based on the deduced sum formula $\left[\mathrm{Al}(\mathrm{OH})\left(\mathrm{O}_{2} \mathrm{C}-\mathrm{C}_{6} \mathrm{H}_{4} \mathrm{OH}-\mathrm{CO}_{2}\right)\right] \cdot 0.5 \mathrm{H}_{2} \mathrm{O}: \mathrm{C} 41.2 \%, \mathrm{H} 2.6$.

The compounds contain no residual chloride or sulfate ions, according to the EDX analysis. The yield is in all cases be- tween $60 \%$ and $70 \%$ based on the amount of linker. Temperature-dependent IR-spectra and Raman-spectra measured under ambient conditions of all compounds can be found in the supporting information (Fig S23-S34).

Structure determination and refinement of 1, 2 and 3 . All compounds were obtained as microcrystalline powders, therefore the structures had to be determined from powder diffraction data.

Indexing of the powder pattern of CAU-10-H (1) suggested a tetragonal cell with the space group $I 4_{1}$. Based on this cell, the structure was solved from in-house XRPD-data by direct methods using the program Expo2009 ${ }^{[25]}$. The inorganic building units were unambiguously located while the organic parts of the framework were inserted as recently described. $^{[28]}$ Utilizing the program Materials Studio ${ }^{[27]}$ the aromatic moieties were introduced at the appropriate positions and the structure was optimized by force-field calculations keeping the positions of the inorganic units fixed. Employing this model as a starting structure, the crystal structure was successfully confirmed by Rietveld-methods using synchrotron XRPD data (Fig. 1). For the measurement at the synchrotron, the sample was heated to $180^{\circ} \mathrm{C}$ to remove adsorbed solvent molecules and filled into a $0.7 \mathrm{~mm}$ capillary which was immediately sealed. This procedure was necessary since the occluded solvent molecules had a strong influence on the observed intensities. Some parameters of this refinement are summarized in Tab.1. Further details are summarized in the supporting information.

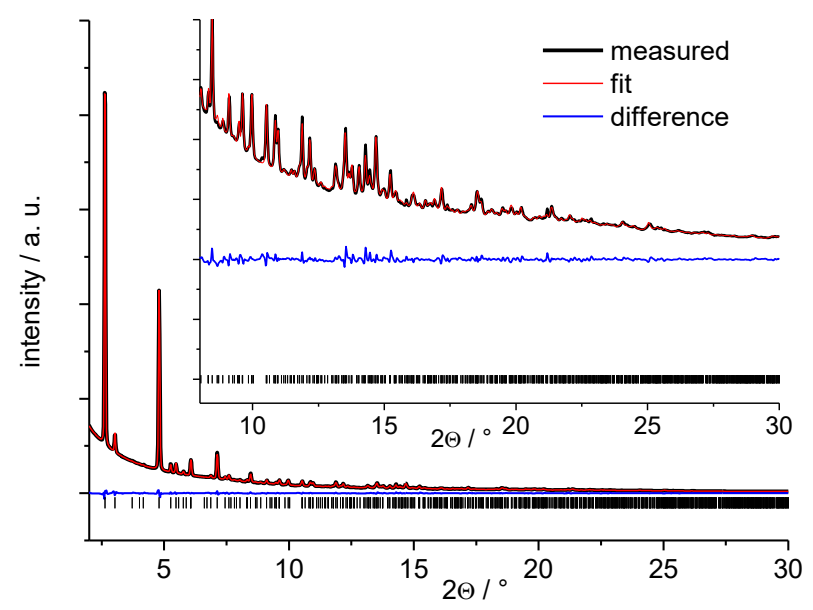

Figure 1: Rietveld plot for the refinement of activated CAU-10$\mathrm{H}(\lambda=0.495 \AA)$. The observed intensities are shown in black, the calculated intensities in red. The blue line is the difference plot, vertical bars mark the Bragg reflection positions.

For CAU-10- $\mathrm{CH}_{3}$ (2), a symmetry transition was observed upon removal of the occluded solvent molecules. The compound crystallizes in a tetragonal cell with extinction conditions matching the chiral space group $P 4_{1}$ in its as (as synthesized)-form (Fig. S4). The chirality was confirmed by second-harmonic generation measurements (vide infra). Heating of 2-as at $200{ }^{\circ} \mathrm{C}$ for one hour in air resulted in small changes in the unit cell parameters. However, indexing of the XRPD pattern led to the space group $I 4_{1} /$ amd. We did not observe any reversibility of this transition under ambient conditions even after several months. The structure of this 
activated compound $\mathbf{2}$ was solved from in-house XRPD-data using Expo2009. All non-hydrogen atoms of the framework were directly obtained from the structure solution. The structural model was refined by Rietveld-methods (Fig. 2, Tab. 1).

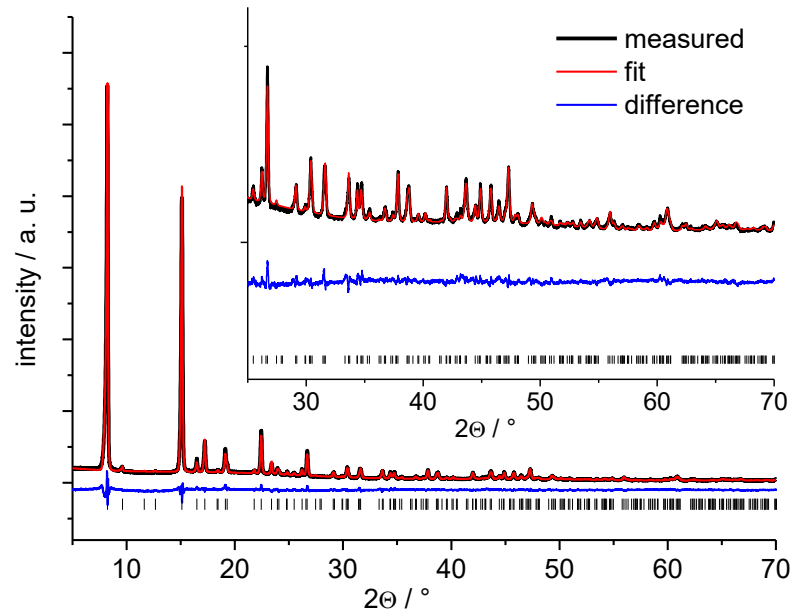

Figure 2: Rietveld plot for the refinement of activated CAU-10$\mathrm{CH} 3$ ( $\mathrm{Cu}-\mathrm{K} \alpha 1$ radiation). The observed intensities are shown in black, the calculated intensities in red. The blue line is the difference plot, vertical bars mark the Bragg reflection positions.

The structure of the $\mathrm{CAU}-10-\mathrm{OCH}_{3}(3)$ was also solved from XRPD-data. The pattern measured for the as synthesized compound could be indexed in the space group $I 4_{1} / a$. Using direct methods, all framework atoms except the methyl group could be located, and therefore the linker molecule was completed using Materials Studio. This model was successfully refined by Rietveld-methods using TOPAS (Fig. 3).

Table 1: Results of the Rietveld refinements.

\begin{tabular}{|l|l|l|l|}
\hline $\mathrm{CAU}-10-\mathrm{X}$ & $-\mathrm{H}(\mathbf{1})$ & $-\mathrm{CH}_{3}(\mathbf{2})$ & $-\mathrm{OCH}_{3}(\mathbf{3})$ \\
\hline space group & $I 4_{1}$ & $I 4_{1} / \mathrm{amd}$ & $I 4_{1} / \mathrm{a}$ \\
\hline$a=b[\AA]$ & $21.55(7)$ & $21.4917(6)$ & $21.3609(3)$ \\
\hline$c[\AA]$ & $10.38(3)$ & $10.1810(5)$ & $10.5699(2)$ \\
\hline $\mathrm{R}_{\mathrm{WP}}$ & 0.019 & 0.071 & 0.076 \\
\hline $\mathrm{R}_{\mathrm{Bragg}}$ & 0.004 & 0.021 & 0.043 \\
\hline $\mathrm{GoF}$ & 2.208 & 2.474 & 2.817 \\
\hline wavelength & $0.495 \AA$ & $\mathrm{Cu} \mathrm{Ka} 1$ & $\mathrm{Cu} \mathrm{Ka}{ }_{1}$ \\
\hline atoms & 28 & 10 & 17 \\
\hline restraints & 45 & 7 & 22 \\
\hline
\end{tabular}

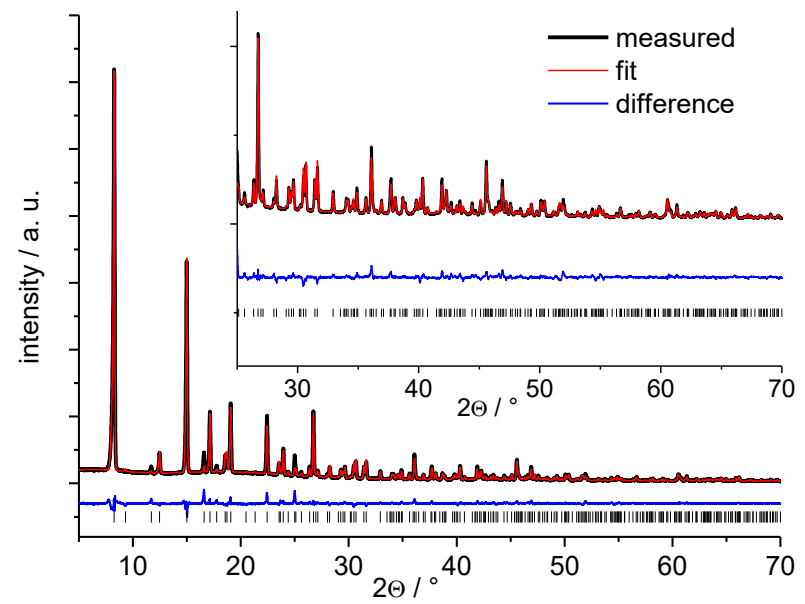

Figure 3: Rietveld plot for the refinement of as synthesized CAU-10-OCH3 (Cu-Kal radiation). The observed intensities are shown in black, the calculated intensities in red. The blue line is the difference plot, vertical bars mark the Bragg reflection positions.

Second-harmonic generation (SHG) or frequency doubling is a second order nonlinear optical process in which photons of frequency $\omega$ are converted in photons with the doubled frequency $2 \omega$. Within the electric dipole approximation, SHG is described by the second-order nonlinear polarization $\mathbf{P}^{(2)}(2 \omega)$ as in following equation:

$$
\mathbf{P}^{(2)}(2 \omega)=\chi^{(2)}: \mathbf{E}(\omega) \mathbf{E}(\omega)
$$

Eq. 1

with $\chi^{(2)}$ the second-order susceptibility and $\mathbf{E}(\omega)$ the electric field of the incoming light at frequency $\omega$. For a centrosymmetric medium the electric field and polarization transform under the action of a centre of inversion as $\mathrm{P} \rightarrow-\mathrm{P}$ and $\mathrm{E} \rightarrow$ -E. This means that equation 1 transforms to

$$
-\mathbf{P}^{(2)}=\chi^{(2)}:(-\mathbf{E})(-\mathbf{E})=\chi^{(2)}: \mathbf{E} \mathbf{E}=\mathbf{P}^{(2)}
$$

which implies that $\chi^{(2)}$ must be zero. Thus centrosymmetric media cannot generate SHG. In fact SHG is especially sensitive to the symmetry relations and organization of a system. As a consequence SHG-microscopy is increasingly used to deduce structural information from materials. Examples include determination of domain structures, ${ }^{29,30}$ host/guest systems $^{31,32}$ and structural transitions. ${ }^{33}$

Recently, a methodology based on polarization dependent SHG-microscopy to determine the point group symmetry of non-centrosymmetric structures has been developed by some of us. ${ }^{34}$ The methodology has been verified experimentally on systems of known symmetry ${ }^{35}$ and employed to determine the symmetry of molecular crystals of unknown structure successfully. ${ }^{36}$

Here we used a derivative methodology, only including the tetragonal non-centrosymmetric point group symmetries. Two polarization dependent tests were used for the determination: in test 1 the plane of polarization of the linearly polarized light incident on the sample is rotated over $360^{\circ}$ while all second-harmonic light is detected, test 2 is identical except that an analyzer is placed in front of the detector, meaning that only the second-harmonic light of one linear polarization is detected. These tests lead to polarization plots 
in which the number of null points - called zeroes ' $z$ ' - and the number of times the plot behaves as an even function around a maximum or minimum intensity can be counted called symmetry axes 'sa'. For monocrystalline, tetragonal structures the expected observables are listed for each point group symmetry. Depending on whether the crystals are aligned with their crystallographic c-axis with the sample plane of the microscope, or have a different (called arbitrary) orientation, these differ, as can be seen in table 2 . As can be seen from this table, the results of test 1 and 2 can be used to distinguish between the different non-centrosymmetric point group symmetries.

If the material is not SHG-active, it means it belongs to a centrosymmetric point group, more specifically $\mathrm{C}_{4 \mathrm{~h}}$ or $\mathrm{D}_{4 \mathrm{~h}}$. Indeed, for activated CAU-10- $\mathrm{CH}_{3}$ (2) and CAU-10-OCH (3), we could detect no SHG-activity, which confirms the space groups assigned via Rietveld refinement of the XRPDdata.

In contrast, for the non-activated compound CAU-10- $\mathrm{CH}_{3}$ (2) we could detect SHG-activity. An SHG-image is shown in figure 5a. To assign a point group symmetry via polarized SHG-microscopy, we need to ensure that the analyzed particles are indeed monocrystalline products. Via scanning electron microscopy we confirmed that structures with a size of several $\mu \mathrm{m}$ with a distinct crystal habit are present (Fig. S38). For the analysis particles in the range of 2-3 $\mu \mathrm{m}$ were selected. In a first step the polarization dependency of the SHG intensity in test 1 and 2 was compared between different parts of the same particle. Only those particles that showed the same (albeit differently scaled) polarization dependence for all parts were chosen. Of these the majority showed the following observables in both test 1 and $2: 0 \mathrm{z}$ and 0 sa. A minority of the particles showed the following observables: $0 \mathrm{z}$ and 4 sa for test 1 , and $0 \mathrm{z}$ and 0 sa for test 2 (see figure $5 b-e$ ). This corresponds to the point group $C_{4}$. The possible space groups derived from the le Bail fit are $P 4_{1}$, and $P 4_{1} 22$ but only the first belongs to the point group symmetry $\mathrm{C}_{4}$. Thus, the SHG-results allow to assign the correct space group and confirm the symmetry transition of CAU-10- $\mathrm{CH}_{3}$ (2) upon activation from a noncentrosymmetric to a centrosymmetric structure. Recently, for amino-functionalized MIL-53(Al) also a symmetry transition that greatly diminshed the SHG-activity was observed, not upon activation, but upon adsorption of guest molecules. $^{37 \mathrm{c}}$

The same analysis was performed for CAU-10-H (1) with qualitatively the same results (Fig. S43), meaning that also this structure belongs to the point group $\mathrm{C}_{4}$, which is also in accordance with the determined space group $I 4_{1}$.

The compounds $\mathbf{4}, \mathbf{5}$ and $\mathbf{6}$ crystallize in primitive tetragonal space groups, as determined by indexing of their powder patterns and the observed extinction conditions. The cell parameters were confirmed by Le Bail-methods for these compounds (Tab. S2, Fig. S5-S7), but due to the crystallographic complexity of these structures it was not possible up to now to refine the structural models. In fact it's also difficult to unambiguously assign a space group by the observed extinction conditions. One reason is the fact, that several space groups show identical extinction conditions in the XRPD-pattern. Moreover, in the case of the CAU-10-series, the differences between the extinction conditions are mar- ginal. Therefore the results of the SHG-measurements greatly enhance the information about the non-refined members of the CAU-10-series.

For compound 5 CAU-10- $\mathrm{NH}_{2}$ no SHG can be detected. This is in accordance with the assignment of a centrosymmetric space group by the Le Bail method. Compound $\mathbf{4}$ and $\mathbf{6}$ also showed SHG-activity, proving their non-centrosymmetric nature. However, SEM images (Fig. S40 and 42) show that only polycrystalline particles are present, meaning that a point group symmetry assignment based on SHGmicroscopy cannot be performed. By XRPD we cannot distinguish the space groups $P 4_{1}$ and $P 4_{1} 22$ for CAU-10-NO (4). However, performing SHG measurements using parallel polarizers a distinction can be made, since only the space group $P 4_{1} 22$ belongs to $\mathrm{D}_{4}$-symmetry. A structure with point group $\mathrm{D}_{4}$ regardless of its orientation cannot generate $\mathrm{SHG}$ when placed between parallel polarizers (SI paragraph VIII). An agglomeration of such structures or polycrystalline sample will neither generate SHG under these conditions, if the plane of polarization of the incident and second-harmonic generated light is not significantly rotated while passing through the polycrystalline particle. The latter condition was experimentally verified When measuring compound 4 between parallel polarizers, a distinct SHG-signal was observed (Fig. 4). Thus the space group $\mathrm{P}_{1}$ is the correct one for this compound. 


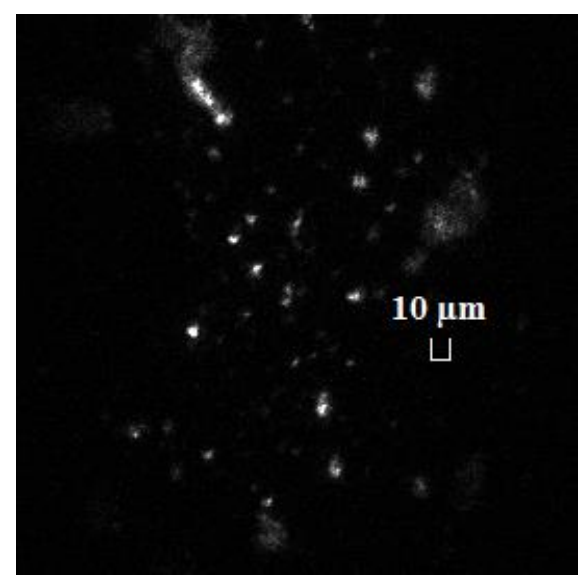

Figure 4: An SHG-image of $\mathrm{CAU}-10-\mathrm{NO}_{2}$ (4) in which the plane of linear polarization of the incident light is parallel with the polarization state that the analyzer at the detection site transmits.
Table 2: Observables in polarization dependent SHGmicroscopy tests for all non-centrosymmetric tetragonal point group symmetries.

\begin{tabular}{|l|l|c|c|}
\hline Point group & orientation* & Test $1^{\dagger}$ & Test2† \\
\hline $\mathrm{C}_{4 \mathrm{v}}$ & all & 0z, 4sa & 0z, 0sa \\
\hline $\mathrm{C}_{4}$ & arbitrary & 0z, 0sa & 0z, 0sa \\
\hline & $\begin{array}{l}\text { c-axis in } \\
\text { sample plane }\end{array}$ & 0z, 4sa & 0z, 0sa \\
\hline $\mathrm{S}_{4}$ & arbitrary & 0z, 0sa & 0z, 0sa \\
\hline & $\begin{array}{l}\text { c-axis in } \\
\text { sample plane }\end{array}$ & $2 \mathrm{z}, 4 \mathrm{sa}$ & $2 \mathrm{z}, 0 \mathrm{sa}$ \\
\hline $\mathrm{D}_{4}$ & all & $2 \mathrm{z}, 4 \mathrm{sa}$ & $4 \mathrm{z}, 4 \mathrm{sa}$ \\
\hline $\mathrm{D}_{2 \mathrm{~d}}$ & arbitrary & 0z, 0sa & 0z, 0sa \\
\hline & $\begin{array}{l}\text { c-axis in } \\
\text { sample plane }\end{array}$ & $2 \mathrm{z}, 4 \mathrm{sa}$ & $2 \mathrm{z}, 0 \mathrm{sa}$ \\
\hline
\end{tabular}

\$ Schoenflies notation $*$ the orientations in which no SHG can be generated were not taken into account. $\dagger \mathrm{z}=$ number of zeros; sa $=$ number of symmetry axis or minima and maxima around which the graphs behaves as an even function; Kleinmann symmetry was not assumed.
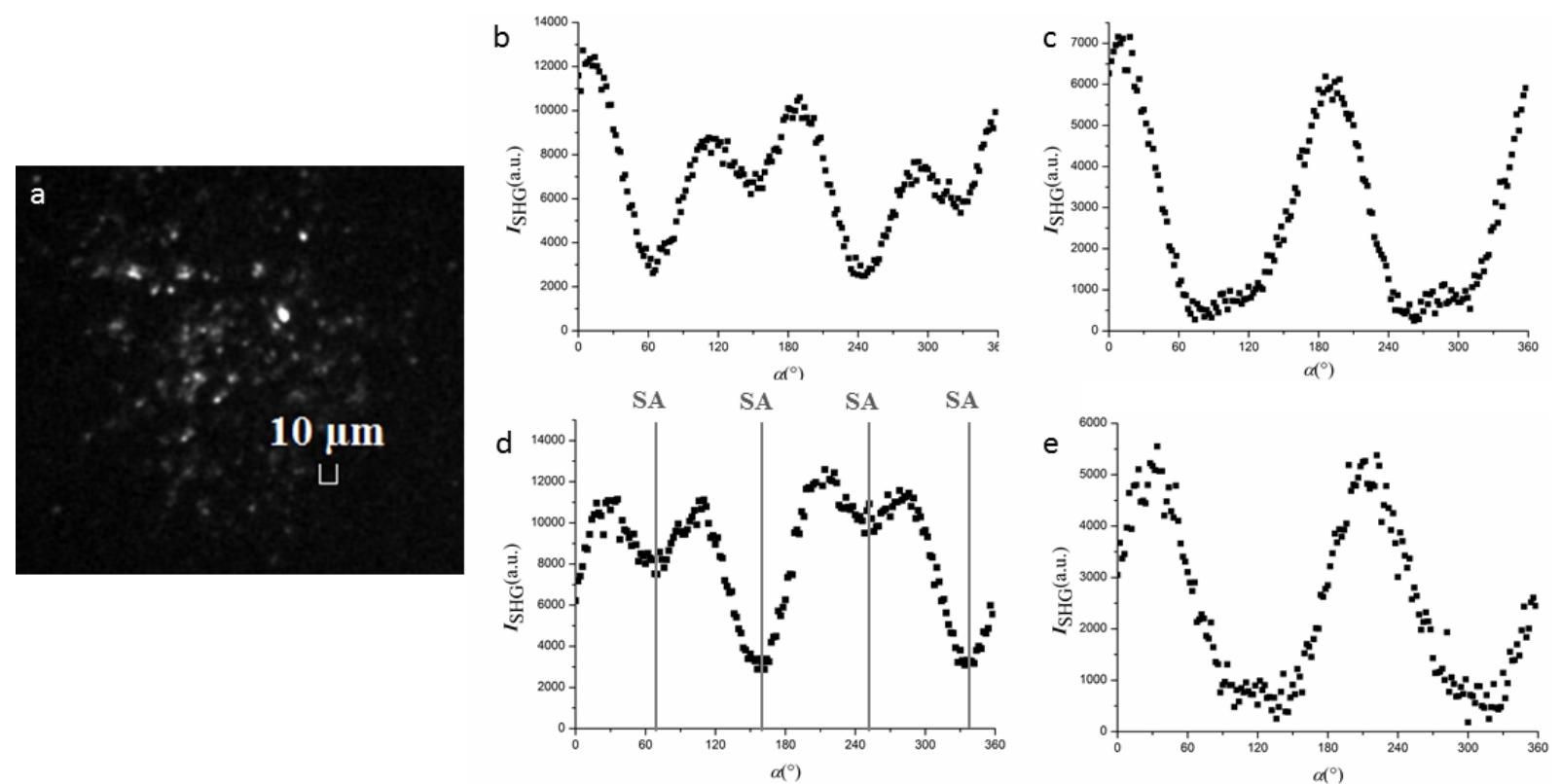

Figure 5: a) SHG-image of as synthesized CAU-10-CH (2). SHG intensity of this structure for tests 1 and 2 resp. corresponding to an arbitrarily oriented crystallite (b and c resp.) and a crystallite oriented with its c-axis aligned with the sample plane (d and e resp.) while varying the plane of polarization of the incident light $(\alpha)$. The incident light is linearly polarized and rotated along the direction of light propagation. Note that when the plane of polarization is $180^{\circ}$ different, the plane of polarization of the incident light is identical.

Structural description. The inorganic building unit of the CAU-10-framework is a chain of cis-connected, corner sharing $\mathrm{AlO}_{6}$-polyhedra. Four of the oxygen atoms are part of four different carboxylate groups, while two bridging $\mathrm{OH}^{-}$ ions in cis-position to each other complete the octahedral coordination of the Al-center. By this connectivity mode, helices are formed (Fig. 6). This helical inorganic building unit is remarkable since most often linear chains of transconnected $\mathrm{M}(\mathrm{III}) \mathrm{O}_{6}$-polyhedra are observed in $\mathrm{MOF}$ with one-dimensional inorganic units. Examples are the framework compounds with MIL-53 topology. Chains of edgesharing $\mathrm{AlO}_{6}$-polyhedra are also known ${ }^{[38]}$ but to the best of our knowledge there are only two Sc-based MOFs which contain such fourfold helical cis-connected chains of $\mathrm{M}(\mathrm{III}) \mathrm{O}_{6}$-polyhedra. ${ }^{[39]}$ 


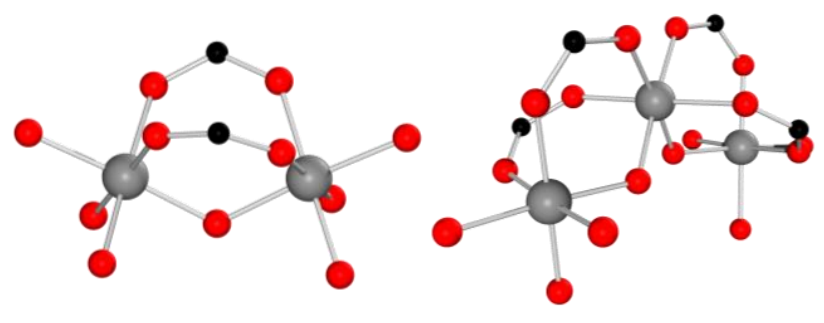

Figure 6: A dimeric unit of corner-sharing $\mathrm{AlO}_{6}$-octahdera on the left. A trimeric subunit is shown on the right, which hints at the formation of a helical arrangement. Aluminium atoms are shown in grey, oxygen in red and carbon in black.

The framework of CAU-10 is formed by the connection of each helix to four adjacent inorganic building units of alternating rotational orientation via the organic linker molecules (Fig.7). Thus, square-shaped, sinusoidal channels are formed, which exhibit a maximum diameter of $\sim 7 \AA$.

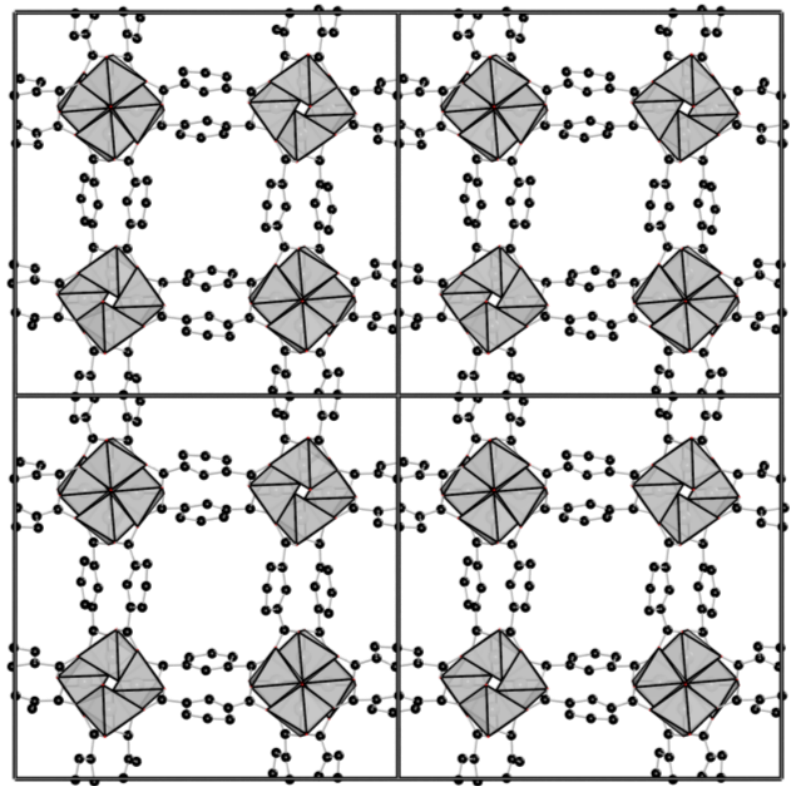

Figure 7: A 2 x 2 supercell of the framework of CAU-10-H (1) as seen along the $c$-axis, showing the fourfold connectivity of the helices and the square-shaped channels that are formed.

Depending on the functional groups, the framework structures are only slightly changed while the topology itself is retained. Due to the size of the channels in the subnanometer range, these small changes have a massive impact on the accessibility of the pores for guest molecules. Therefore the structures of $\mathbf{2}$ and $\mathbf{3}$ are described herein in detail. While two symmetry independent helixes are observed in $\mathbf{1}$, the change of the linker molecules to methylisophthalic acid in 2 leads to a more symmetric structure $\left(I 4_{1}\right.$ vs. I4 $4_{1} /$ amd $)$. The adjacent $\mathrm{AlO}_{6}$-helices are related by a mirror plane which is parallel to the b-c-plane (Fig. 8) and passes through the carbon atoms in 2- and 5-position and the methyl-group of the organic moieties.

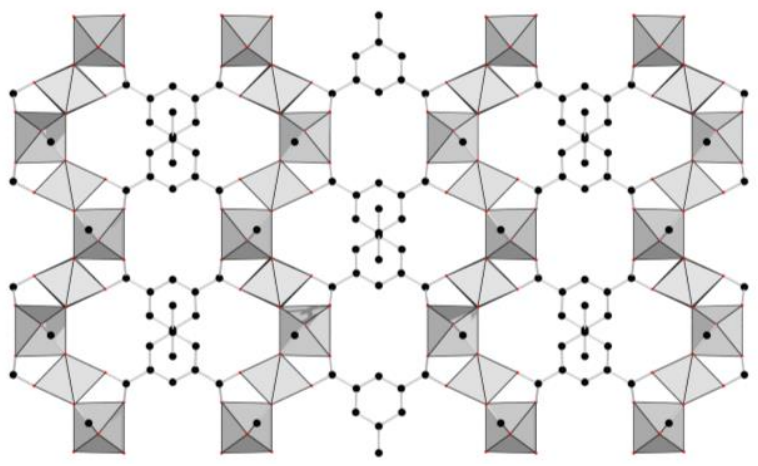

Figure 8: The arrangement of the helices in the framework of CAU-10- $\mathrm{CH}_{3}$ (2) as seen along the $b$-axis. $\mathrm{AlO}_{6}$-polyhedra are shown in grey, oxygen atoms in red and carbon atoms in black.

In the structure of $\mathrm{CAU}-10-\mathrm{OCH}_{3}(3)$ which crystallizes in the space group $I 4_{1} / a$, only one crystallographically independent helix is observed. The helices are related by an inversion axis, which is running parallel to the $c$-axis between four helices (Fig.9).

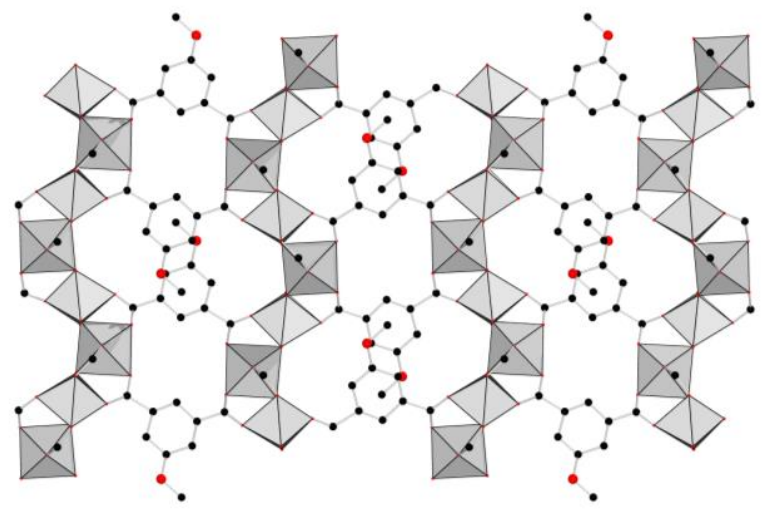

Figure 9: The arrangement of the helices in the framework of CAU-10- $\mathrm{OCH}_{3}(3)$ as seen along the $b$-axis. $\mathrm{AlO}_{6}$-octahedra are shown in grey, oxygen atoms in red and carbon atoms in black.

The different arrangements of the helices result as well in different alignments of the organic building units. The framework of CAU-10- $\mathrm{CH}_{3}(2)$ has the structure of highest symmetry. This results in functional groups which are protruding directly into the channels (Fig. 10, right). The shortest distance between two methyl-carbon atoms is $5.8 \AA$ (center to center). The lower symmetry in CAU-10-OCH $\mathrm{CH}_{3}$ (3) results in a distortion of the framework, which gives rise to a slightly larger distance between the oxygen-atoms of the functional groups of $6.4 \AA$ (center to center) (Fig. 10, left). In CAU-10-H (1), the distance of the aromatic carbon atoms in 5-position is $6.8 \AA$.

The exact structures of the $\mathrm{NO}_{2^{-}}, \mathrm{NH}_{2^{-}}$and $\mathrm{OH}-$ functionalized MOFs remain yet unknown due to their crystallographic complexity and/or the rather insufficient crystallinity. However, the sorption behavior points at structural similarities between CAU-10- $\mathrm{NO}_{2}$ (4) and CAU-10-H (1) as well as CAU-10-NH $\mathrm{NH}_{2}$ (5) / CAU-10-OH (6) and CAU-10$\mathrm{CH}_{3}(2) / \mathrm{CAU}-10-\mathrm{OCH}_{3}(3)$. 


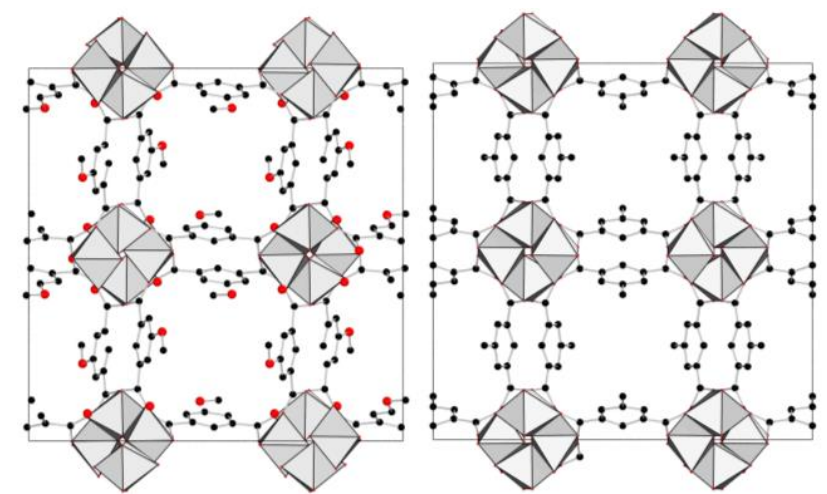

Figure 10: Direct comparison of the framework structures of CAU-10-OCH3 on the left and CAU-10-CH3 on the right, as seen along the c-axis. AlO6-octahedra are shown in grey, oxygen atoms in red and carbon atoms in black.

The differences in the CAU-10-X structures are due to a combination of the differences in the steric requirements of the functional groups and the interactions (inter ring distances $<3.4 \AA$ ) of the aromatic moieties.

We object to the framework topology of CAU-10 as an archetype, which should be likely to form with several other trivalent cations as well as further $\mathrm{V}$-shaped linker molecules, in analogy to the diversity observed for MIL-53topology. This is supported by the recent discovery of a very similar MOF based on $\mathrm{Sc}^{3+}$ and the $\mathrm{V}$-shaped 2,5thiophenedicarboxylic acid. ${ }^{[39]}$

Sorption behaviour. The subtle structural differences of these microporous compounds, i.e. the diameter of the pore aperture and the flexibility of the organic building units should result in drastically altered sorption properties. Therefore, the sorption behavior of all six members of the CAU10 -series in the low pressure regime (up to 1 bar) was measured using nitrogen and hydrogen at $-196{ }^{\circ} \mathrm{C}$ and carbon dioxide and water vapor at $25{ }^{\circ} \mathrm{C}$. Prior to every measurement, the samples were activated in vacuum (o.1 mbar) at $200{ }^{\circ} \mathrm{C}$. The sorption isotherms for $\mathrm{N}_{2}$ at $-196{ }^{\circ} \mathrm{C}$ are shown in Figure 11. For CAU-10-H (1) and CAU-10-NO $\mathrm{NO}_{2}$ (4), a type I isotherms was observed, indicating microporosity.

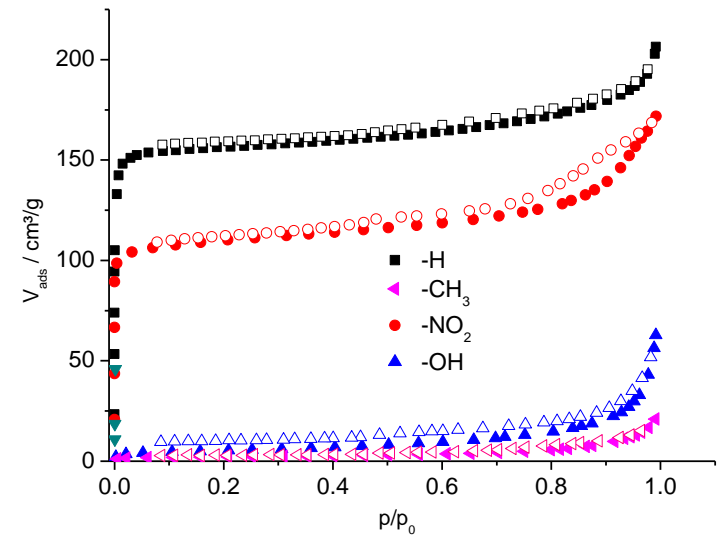

Figure 11: Sorption isotherms of CAU-10-X compounds for nitrogen at $-196{ }^{\circ} \mathrm{C}$. Filled symbols represent the adsorption, empty symbols the desorption branches.
While we observed isotherms typical for non porous compounds for 2 and $6\left(-\mathrm{CH}_{3}\right.$ and $\left.-\mathrm{OH}\right)$, for CAU-10-OCH $(3)$ and $-\mathrm{NH}_{2}(\mathbf{5})$ (not shown) only an initial uptake of gas was measured. Due to the very slow equilibration, it was not possible to measure full curves for $\mathbf{3}$ and $\mathbf{5}$ with appropriate precision. However, higher tolerance values for the pressure fluctuation during the measurements hint at the existence of accessible micropores. We attribute this behavior to the narrow channels, which slow down the free diffusion of gas molecules in case of $\mathrm{N}_{2}$-adsorption, and thus extend the equilibration times. Thus, the functional groups have a massive impact on the accessibility of the channels in the case of $\mathrm{N}_{2}$-sorption. The specific surface areas $\mathrm{S}_{\mathrm{BET}}$ are $635 \mathrm{~m}^{2} / \mathrm{g}$ and $440 \mathrm{~m}^{2} / \mathrm{g}$ for CAU-10-H (1) and CAU-10-NO 2 (4), respectively. Their micropore volumes, determined by single point calculation at $\mathrm{p} / \mathrm{p}_{0}=0.5$, are $0.25 \mathrm{~cm}^{3} / \mathrm{g}$ (for 1 ) and $0.18 \mathrm{~cm}^{3} / \mathrm{g}$ (for 4). The experimental value for the CAU-10-H (1) is in very good agreement with the theoretical pore volume of $0.23 \mathrm{~cm}^{3} / \mathrm{g}$ as obtained from a single point adsorption simulation by force-field methods. ${ }^{[40]}$

The curves for the hydrogen adsorption show an uptake of this gas for all members of the series except CAU-10- $\mathrm{CH}_{3}$ (2) (Fig. 12).

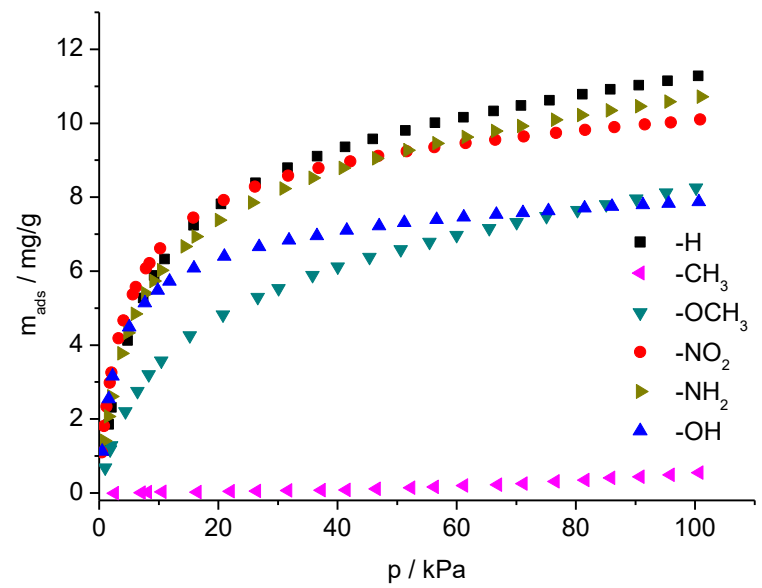

Figure 12: Adsorption isotherms of $\mathbf{1}$ - $\mathbf{6}$ for hydrogen at -196 ${ }^{\circ} \mathrm{C}$.

The influence of the functional groups on the adsorption is clearly demonstrated. Their impact on the capacity is not only due to their size but also to the subtle structural differences caused by these groups. Moreover the affinity towards $\mathrm{H}_{2}$ is varied. Although the micropore volumes of CAU-10-H (1) and CAU-10- $\mathrm{NO}_{2}$ (4) differ substantially, similar $\mathrm{H}_{2}$ uptakes at pressures below $40 \mathrm{kPa}$ are observed. The reason for this result is probably the polar nature of the functional group, which induces a stronger affinity towards $\mathrm{H}_{2}$ in 4 . The accessibility of the channels for $\mathrm{H}_{2}$ molecules is hardly influenced due to its smaller kinetic diameter $\left(\mathrm{N}_{2}: 3.6 \AA, \mathrm{H}_{2}: 2.6\right.$ $\AA$ ), except for CAU-10- $\mathrm{CH}_{3}$ (2).

The adsorption isotherms for $\mathrm{CO}_{2}$ were measured at $25{ }^{\circ} \mathrm{C}$ and clearly prove the porosity of all members of the CAU10-series (Fig. 13). 


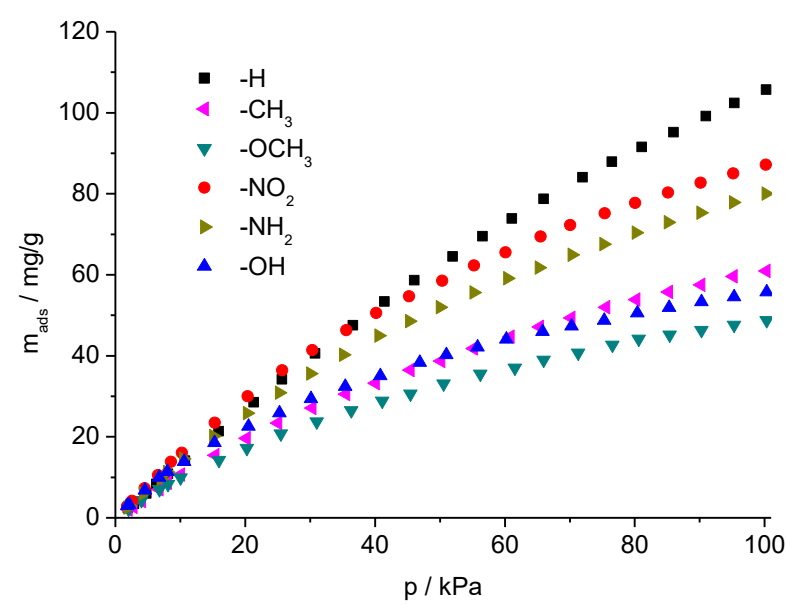

Figure 13: Adsorption isotherms for $\mathrm{CO}_{2}$ at $25^{\circ} \mathrm{C}$.

Even the pores of CAU-10- $\mathrm{CH}_{3}$ (2) are accessible towards $\mathrm{CO}_{2}$ molecules which can be attributed to the higher experimental temperature of $25^{\circ} \mathrm{C}$ and stronger host-guest interactions. Although the kinetic diameter of $\mathrm{CO}_{2}$ molecules (3.3 $\AA$ ) is larger than the one of $\mathrm{H}_{2}$ molecules $(2.6 \AA)$, the increased flexibility of the framework at $25{ }^{\circ} \mathrm{C}$ makes the pores of $\mathbf{2}$ accessible for $\mathrm{CO}_{2}$, while $\mathrm{H}_{2}$ is not adsorbed at $-196{ }^{\circ} \mathrm{C}$. Similar trends for capacities are found, as observed for the $\mathrm{H}_{2}$ adsorption. In comparison with the unfunctionalized compound $\mathbf{1}$, substantially lower uptakes of gas are observed for 2,3 and 6 . The $\mathrm{NO}_{2}$-group in 4 and the $\mathrm{NH}_{2-}$ group in $\mathbf{5}$ lead to intermediate capacities for these two MOFs.

A pronounced influence of the functional groups was observed for the adsorption of water vapor, measured at $25^{\circ} \mathrm{C}$ (Fig. 14)

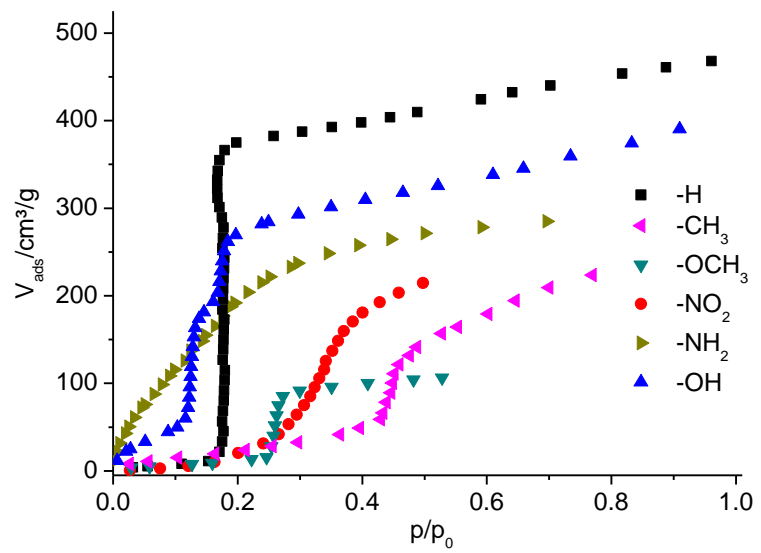

Figure 14: Adsorption isotherms of $\mathbf{1}$ - 6 for $\mathrm{H}_{2} \mathrm{O}$ at $25^{\circ} \mathrm{C}$.

All MOFs show an uptake of water vapor and the amount is mainly determined by the size of the functional group. CAU$10-\mathrm{NH}_{2}(5)$ and CAU-10-OH (6) show pronounced uptakes of $\mathrm{H}_{2} \mathrm{O}$ molecules at low relative pressure which can be explained by the existence of strong hydrogen-bonds between the functional groups in the MOF and the adsorptive (the broad band of the hydrogen-bonded water molecules are visible for non-dehydrated sample in the IR-spectra - Fig. S31, S33). Besides this, the point of condensation, at which the pores are filled with liquid adsorbate, is altered by the functionalization. The highest affinity towards $\mathrm{H}_{2} \mathrm{O}$ is observed for the highly polar groups in CAU-10-NH $\mathrm{NH}_{2}(\mathbf{5})$ and CAU-10-OH (6). The exact amounts of $\mathrm{H}_{2}$ and $\mathrm{CO}_{2}$ adsorbed at $100 \mathrm{kPa}$ and the amount of $\mathrm{H}_{2} \mathrm{O}$ that was adsorbed after condensation are summarized in Table 3.

Table 3: Total amounts of adsorbed gas or vapour.

\begin{tabular}{|l|l|l|l|}
\hline $\mathrm{R}$ & $\begin{array}{l}\mathrm{H}_{2}[\mathrm{mg} / \mathrm{g}] \\
(\text { at } 100 \mathrm{kPa})\end{array}$ & $\begin{array}{l}\mathrm{CO}_{2}[\mathrm{mg} / \mathrm{g}] \\
(\text { at } 100 \mathrm{kPa})\end{array}$ & $\begin{array}{l}\mathrm{H}_{2} \mathrm{O} \quad\left[\mathrm{cm}^{3} / \mathrm{g}\right] \\
\left.\text { at } \mathrm{p} / \mathrm{p}_{0}=\right)\end{array}$ \\
\hline$-\mathrm{H}$ & 11.2 & 105.7 & $382(\mathrm{o.26})$ \\
\hline$-\mathrm{CH}_{3}$ & 0.5 & 60.9 & $140(0.48)$ \\
\hline$-\mathrm{OCH}_{3}$ & 8.2 & 48.7 & $92(0.30)$ \\
\hline$-\mathrm{NO}_{2}$ & 10.1 & 87.1 & $181(0.40)$ \\
\hline$-\mathrm{NH}_{2}$ & 10.7 & 80.0 & $271(0.50)$ \\
\hline$-\mathrm{OH}$ & 7.9 & 55.7 & $284(0.25)$ \\
\hline
\end{tabular}

Interestingly, the high affinity observed during water adsorption is not reflected during the activation of the series of CAU-10-X samples as observed in the IR-spectra. For all the samples, molecular water is removed already during evacuation at RT. The fingerprint region of the CAU-10-X are not changed after water desorption (Fig. S23-S34). This suggests that dehydration leads at most to minor changes in the structure.

Correlation of Sorption Properties and Structure. In the framework of CAU-10-H (1), the channels are open and easily accessible for all measured gas molecules. The framework of CAU-10- $\mathrm{CH}_{3}(2)$ is only able to adsorb $\mathrm{CO}_{2}$ at $25{ }^{\circ} \mathrm{C}$, but at $-196{ }^{\circ} \mathrm{C}$, no adsorption could be observed. In CAU-10- $\mathrm{OCH}_{3}(3)$, the size of the adsorbate seems to be the crucial parameter which determines the accessibility of the pores. To understand this sorption behavior, the $\mathrm{H}$-atoms must be added to the framework structure. This was accomplished by an automatic algorithm implemented in the Materials Studio software. ${ }^{[27]}$

The van-der-Waals-model of CAU-10- $\mathrm{CH}_{3}$ (2) shows, that only a very small aperture with a diameter of $1.4 \AA$ allows the diffusion into the channels (Fig. 15).
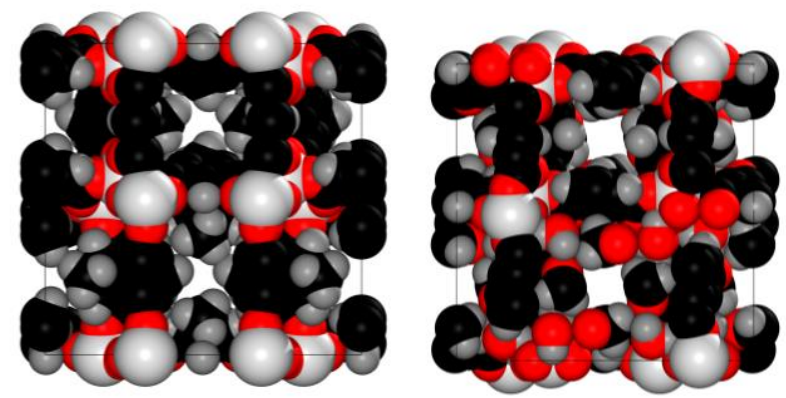

Figure 15: Unit cell of CAU-10- $\mathrm{CH}_{3}$ (2) on the left and CAU$10-\mathrm{OCH}_{3}(3)$ on the right, shown as van-der-Waals models. Aluminium atoms are light grey, oxygen atoms are red, carbon atoms are black and hydrogen atoms are dark grey.

In the framework of CAU-10- $\mathrm{OCH}_{3}(3)$, this smallest diameter is $2.5 \AA$. This increase of the diameter by $\sim 1 \AA$ is mainly 
due to the functional group. In 2, the protons of the methylgroup limit the accessibility. In $\mathbf{3}$, the hydrogen atoms can be almost neglected, since the unprotonated oxygen-atoms of the methoxy-groups are limiting the diameter of the aperture (Fig.12). In the unfunctionalized CAU-10-H (1), the accessible diameter according to the crystal structure is $4 \AA$, which allows the adsorption of all measured gases (Fig. 16).

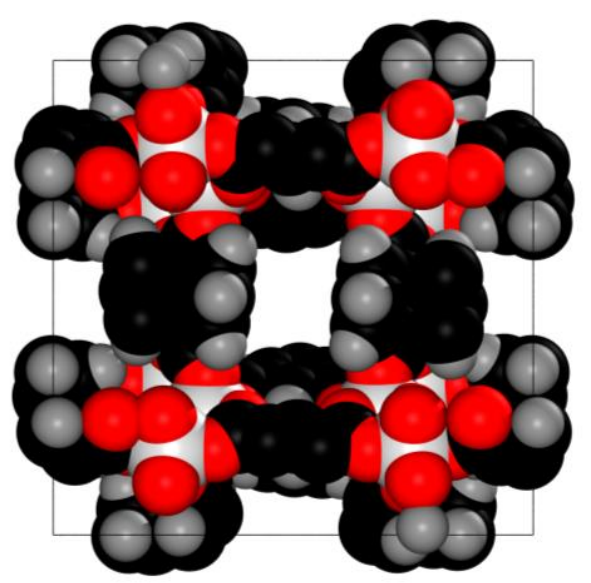

Figure 16: Van-der-Waals model of CAU-10-H (1). Aluminium atoms are light grey, oxygen atoms are red, carbon atoms are black and hydrogen atoms are dark grey.

Therefore, the accessibility of $\mathbf{1}$ for all gases is in agreement with its crystal structure. For CAU-10- $\mathrm{OCH}_{3}(3)$, we must assume that the framework possesses a certain degree of flexibility, since the kinetic diameters of the gas molecules are larger than the channel openings. In the framework of CAU-10- $\mathrm{CH}_{3}$ (2), the flexibility of the MOF must be even higher than in $\mathbf{3}$, since the pore opening is smaller. Therefore, only at an elevated temperature of $25^{\circ} \mathrm{C}$, gas molecules can be adsorbed in 2 . At $-196{ }^{\circ} \mathrm{C}$, its flexibility is too low to permit the adsorption of gases. An additional influence on this sorption behavior is given for sure by the higher mobility of the gas molecules at $25{ }^{\circ} \mathrm{C}$ compared with $-196{ }^{\circ} \mathrm{C}$. However, since the pore diameter is nevertheless limiting the accessibility of the channels, we consider the framework flexibility as a crucial parameter.

Stability measurements. The stabilities in aqueous solutions depending on the $\mathrm{pH}$-value as well as under solvothermal conditions in water were investigated by XRPD- and IRmeasurements (Fig. S11-S16). For these tests, $50 \mathrm{mg}$ of each MOF were stirred for 18 hours at room temperature in $4 \mathrm{~mL}$ of $0.01 \mathrm{M}$ hydrochloric acid or $0.01 \mathrm{M}$ sodium hydroxide solution. According to these results, the MOFs are stable in a $\mathrm{pH}$-range from 2 to 8 . Stirring under more basic conditions does not lead to a complete decomposition, but the $\mathrm{pH}$-value is lowered to 8 , indicating that the compounds are dissolved until a final $\mathrm{pH}$-value of 8 is reached. The treatment in acidic solution ( $\mathrm{pH}$ of 2), does not lead to additional bands in the IR-spectra, indicating that no isophthalic acid derivatives are formed by solvolysis of the MOFs, confirming their stability. Upon treatment with water at $130{ }^{\circ} \mathrm{C}$ under stirring for 3 hours, no decomposition is observed as well. This stability is lower compared to the series of zirconium based $\mathrm{MOFs}^{[7]}$ but it is nevertheless very remarkable, especially in comparison with several MOFs based on divalent metal ions. ${ }^{[18]}$

According to the thermogravimetric experiments, all of the MOFs decompose at temperatures around $400{ }^{\circ} \mathrm{C}$ (Fig. S17$\mathrm{S} 22)$. The temperature dependent XRPD-measurements for CAU-10-H (1) show a decomposition at $\sim 430{ }^{\circ} \mathrm{C}$ (Fig. 17 and Fig. S8). While the removal of the adsorbed solvent molecules leads to changes in the relative intensities, the broadening of the reflections at $430{ }^{\circ} \mathrm{C}$ marks the beginning of the decomposition of the framework. These observations were also supported by temperature-dependent FTIR spectroscopy (see SI).

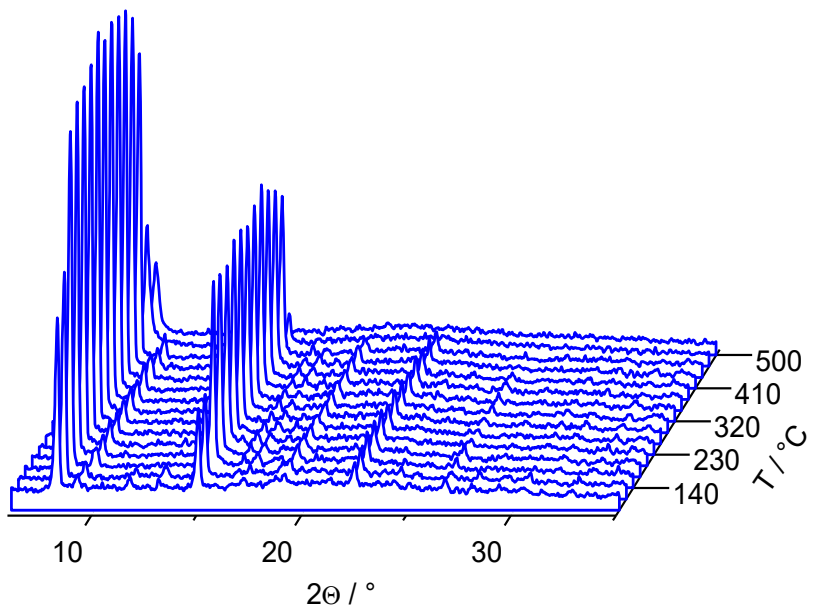

Figure 17: Temperature dependent XRPD-data of CAU-10-H measured in a capillary.

For CAU-10-NO $\mathrm{NO}_{2}$ (4) and CAU-10-OH (6) we observed similarly high thermal stabilities in the temperature dependent XRPD-measurements (Fig. S9-S10). The decomposition starts at temperatures above $410{ }^{\circ} \mathrm{C}$. During the heating, we observed almost no shift of the reflections for $\mathbf{1}$. For $\mathbf{4}$, a shift towards lower angles is observed. Thus, the unit cell of CAU-10- $\mathrm{NO}_{2}(4)$ is slightly expanding upon heating while it remains rather rigid in case of CAU-10-H (1).

A slightly lower stability is observed in the temperature dependent IR-spectra (Fig. S23-S33), mainly attributed to the different measurement conditions in vacuum. Thus CAU-10$\mathrm{H}$ (1) and CAU-10- $\mathrm{CH}_{3}$ (2) decompose at $350{ }^{\circ} \mathrm{C}$, while the decomposition of CAU-10-NO $\mathrm{NO}_{2}(\mathbf{4})$ starts already at $300{ }^{\circ} \mathrm{C}$ in vacuum. From the CAU-10-series, CAU-10- $\mathrm{NH}_{2}$ (5) and $\mathrm{CAU}-10-\mathrm{OCH}_{3}$ (3) revealed the highest thermal stability under vacuum, decomposing only at $450{ }^{\circ} \mathrm{C}$. The lowest stability was observed for CAU-10-OH (6), for which sample damage appeared already at $250{ }^{\circ} \mathrm{C}$. The lower stability compared to XRPD experiments can be attributed to the different measurement conditions. Temperature dependent IR spectra allowed also to follow the removal of traces of DMF and water molecules occluded inside the pores, which are removed up to $150{ }^{\circ} \mathrm{C}$. In neither sample free isophthalic acid was observed in the IR-spectra.

Nonlinear optical properties. While inorganic materials are still nearly exclusively used in practical applications of nonlinear optical (NLO) materials, it is widely recognized that 
molecular-based materials can surpass these materials in their nonlinear optical characteristics: ultrafast response times, higher NLO-responses and a better processibility into devices. ${ }^{41,42}$ Metal-organic frameworks have been investigated as a route to obtain nonlinear optical molecular-based materials. $^{43,44}$

We quantified the SHG-response for the structure that has the highest SHG activity, namely CAU-10- $\mathrm{NO}_{2}$ (4). Assuming monocrystalline particles, the effective second order nonlinear optical coefficient averaged over all orientations $\left\langle\mathrm{d}_{\text {eff }}\right\rangle$ was found to be $0.0002 \mathrm{pm} / \mathrm{V}$ (SI paragraph X). However, the generated SHG intensity scales quadratically with the thickness of a single crystal, but only linearly with the number of crystallites. As the CAU-10- $\mathrm{NO}_{2}$ (4) sample consists in fact of a polycrystalline powder, this determined value is an underestimation of the effective nonlinear optical coefficient with at least several orders of magnitude. Typical commercial NLO materials (such as KDP, BBO, KTP and $\mathrm{LiIO}_{3}$ ) show $\mathrm{d}_{\text {eff }}$ values between 0.4 and $15 \mathrm{pm} / \mathrm{V}$. The true value of $\mathrm{d}_{\mathrm{eff}} \mathrm{CAU}-10-\mathrm{NO}_{2}$ (4) will likely be in this range.

The origin of the observed non-centrosymmetry must be attributed to the functional groups. While activated CAU-10$\mathrm{CH}_{3}$ (2) exhibits the space group of highest symmetry $I 4_{1} /$ amd, the interactions between the linker molecules (distance between adjacent linker molecules $<3.4 \AA$ ) in the other MOFs induce a distortion of this ideal structure to space groups with lower symmetry which are subgroups of $I 4_{1} /$ amd. Another reason for this observation may be the existence of guest molecules inside the channels. For example, CAU-10- $\mathrm{CH}_{3}$ containing $\mathrm{H}_{2} \mathrm{O}$ crystallizes in the noncentrosymmetric space group $\mathrm{P}_{1}$. After thermal activation CAU-10- $\mathrm{CH}_{3}$ is found to crystallise in the centrosymmetric space group $I 4_{1} /$ amd. Therefore, the interactions inducing the SHG-activity are complex and can't be attributed to one clearly defined interaction as observed in other MOFs. ${ }^{45}$

\section{Conclusions}

Summarizing the results, a series of six MOFs was synthesized exhibiting the same framework topology, but different functional groups. The detailed characterisation clearly shows that subtle structural differences have a massive impact on the sorption capacity and affinity, as well as on the second-order nonlinear optical activity. The combination of XRPD and SHG measurements allows following structural changes upon activation and the determination of the correct space group. The straightforward synthesis of the compounds under very similar reaction conditions could be helpful in tuning the sorption properties by using mixed linker systems. Moreover the topology of the CAU-10-series could be starting point for the synthesis of isoreticular compounds based on V-shaped ligands and trivalent cations. This would expand the range of opportunities for the modulation of the sorption behavior.

Supporting Information available. Crystallographic data and details about the refinements, Le Bail-fits, results of the thermogravimetric measurements, XRPD-data for the stability tests, temperature dependent IR-spectra and Raman-spectra under ambient conditions, NMR-spectra, the description of the HT- experiments, SEM-images, additional SHG-data and the theoretical treatment of the SHG results. This material is available free of charge via the Internet at http://pubs.acs.org.

\section{AUTHOR INFORMATION}

\section{Corresponding Author}

* Norbert Stock, Institut für Anorganische Chemie, ChristianAlbrechts-Universität zu Kiel, Max-Eyth-Straße 2, D-24118 Kiel, Germany; stock@ac.uni-kiel.de Monique van der Veen, Centre for Surface Chemistry and Catalysis KU Leuven, Kasteelpark Arenberg 23-bus 2461, 3001Leuven, Belgium; Monique.VanderVeen@ biw.kuleuven.be

\section{Funding Sources}

This work has been supported by the DFG (SPP 1362). The research leading to these results has received funding from the European Community's Seventh Framework Programme (FP7/2007-2013) under grant agreement no 228862. The IR studies (BG and BM) were carried out with the equipment purchased thanks to the financial support of the European Regional Development Fund in the framework of the Polish Innovation Economy Operational Program (contract no. POIG.02.01.00-12023/08). MAvdV thanks the FWO Vlaanderen for a postdoctoral fellowship. TV and MAvdV acknowledge financial support from the KU Leuven (GOA).

\section{ACKNOWLEDGMENT}

The help of Christin Szillus and Lorenz Kienle (CAU Kiel) recording the SEM-micrographs is gratefully acknowledged. We thank master student Ward Ceunen for performing part of the SHG-mesurements under the guidance of MAvdV.

\section{REFERENCES}

1 Morris, R. E.; Wheatley, P. E., Angew. Chem. Int. Edt 2008, 47, 4966-4981.

2 Li, J. R.; Kuppler, R. J.; Zhou, H. C.; Chem. Soc. Rev. 2009, 38, 1477-1504.

3 Kreno, L. E.; Leong, K.; Farha, O. K.; Allendorf, M.; Van Duyne, R. P.; Hupp, J. T.; Chem. Rev. 2012, 112, 1105-1125.

$4 \quad$ Horcajada, P.; Gref, R.; Baati, T.; Allan, P. K.; Maurin, G.; Couvreur, P.; Férey, G.; Morris, R. E.; Serre, C. ; Chem. Rev. 2012, 112, 1232-1268.

5 O'Keeffe, M.; Chem. Soc. Rev. 2009, 38, 1215-1217.

6 Cavka, J. H., Jakobsen, S., Olsbye, U., Guillou, N., Lamberti, C., Bordiga, S., Lillerud, K. P., J. Am. Chem. Soc. 2008, 130, 13850-13851.

7 Schaate, A.; Roy, P.; Godt, A.; Lippke, J.; Waltz, F.; Wiebcke, M.; Behrens, P.; Chem. Eur. J. 2011, 17, 6643-6651.

8 Loiseau, T. ; Serre, C. ; Huguenard, C. ; Fink, G. ; Taulelle, F.; Henry, M. ; Bataille, T. ; Ferey, G. ; Chem. Eur. J. 2004, 10, 1373-1382.

9 Gaab, M.; Trukhan, N.; Maurer, S.; Gummaraju, R. ; Müller, U.; Micropor. Mesopor. Mater. 2012, 157, 131-136.

10 Senkovska, I.; Hoffmann, F.; Fröba, M.; Getzschmann, J.; Böhlmann, W.; Kaskel, S.; Micropor. Mesopor. Mater., 2009 122, 93-98.

11 Devic, T.; Horcajada, P.; Serre, C.; Salles, F.; Maurin, G.; Moulin, B.; Heurtaux, D.; Clet, G.; Vimont, A.; Greneche, J.M.; Le Ouay, B.; Moreau, F.; Magnier, E.; Filinchuk, Y.; 
Marrot, J.; Lavalley, J.-C.; Daturi, M.; Ferey, G.; J. Am. Chem. Soc., 2010, 132, 1127-1136.

12 Biswas, S.; Ahnfeldt, T.; Stock, N.; Inorg. Chem. 2011, 50, 9518-9526.

13 Mowat, J. P. S.; Miller, S. R.; Slawin, A. M. Z.; Seymour, V. R.; Ashbrook, S. E.; Wright, P. A.; Micropor. Mesopor. Mater. 2011, 142, 322-333.

14 Whitfield, T. R.; Wang, X.; Liu, L.; Jacobson, A. J.; Solid State Sci. 2005, 7, 1096-1103.

15 Serre, C. ; Millange, F. ; Thouvenot, C. ; Noguès, M. ; Marsolier, G. ; Louër, D. ; Férey, G. ; J. Am. Chem. Soc. 2002, 124, 13519-13526.

16 Anokhina, E. V. ; Vougo-Zanda, M. ; Wang, X. ; Jacobson, A. J. ; J. Am. Chem. Soc. 2005, 127, 15000-15001.

17 Volkringer, C. ; Loiseau, T. ; Guillou, N. ; Férey, G. ; Elkaïm, E. ; Vimont, A. ; Dalton Trans. 2009, 12, 2241-2249.

18 Cychosz, K. A.; Matzger, A. J.; Langmuir 2010, 26, 1719817202.

19 Bernt, S. ; Guillerm, V.; Serre, C.; Stock, N.; Chem. Commun. 2011, 47, 2838-2840.

20 Stock, N.; Micropor. Mesopor. Mater. 2010, 129, 287-295.

21 Stock, N.; Biswas,S.; Chem. Rev. 2012, 112, 933-969.

22 Biemmi, E.; Christian, S.; Stock, N.; Bein, T.; Micropor. Mesopor. Mater. 2009, 117, 111-117.

23 Hammersley, A. P.; Svensson, S. O.; Hanfland, M.; Fitch, A. N.; Häusermann, D.; High Pressure Research 1996, 14, 235248.

24 Ahnfeldt, T.; Guillou, N.; Gunzelmann, D.; Margiolaki, I.; Loiseau, T.; Férey, G.; Senker, J.; Stock, N.; Angew. Chem. Int. Ed. 2009, 28, 5163-5166.

25 Altomare, A.; Camalli, M.; Cuocci, C.; Giacovazzo, C.; Moliterni, A.; Rizzi, R.; J. Appl. Cryst. 2009, 42, 1197-1202.

26 Topas Academics 4.2, Coelho Software, 2007.

27 Materials Studio Version 5.0, Accelrys Inc., San Diego, CA, 2009.

28 Reinsch, H.; Feyand, M.; Ahnfeldt, T.; Stock, N.; Dalton Trans. 2012, 41, 4164-4171.

29 Kim, H.; Lim, T.K.;Shin, S.T.; Lee, C.K.;Araoka, F.;Ofuji, M.;Takanishi,Y.;Takezoe, H., Phys. Rev. E 2004, 69, 061701.

30 Kaneshiro, J.; Kawado, S.; Yokota, H.; Uesu, Y.; Fukui, T., J. Appl. Phys. 2008, 104, 054112.

31 van der Veen, M.A.; Sels, B.F.; De Vos, D.E.; Verbiest, T., J. Am. Chem. Soc. 2010, 132, 6630-6631.

32 van der Veen, M.A.; Van Noyen, J.; Sels, B.F.; Jacobs, P.A.; Verbiest, T.; De Vos, D.E., Phys. Chem. Chem. Phys. 2010, 12, 10688-10692.

33 De Sa Peixoto, P.; Deniset-Besseau, A.; Schanne-Kleinb, M.C.; Mosser G., Soft Matter 2011, 7, 11203-11210.

34 van der Veen, M.A. Vermoortele, F., De Vos, D.E., Verbiest, T., Anal. Chem., 2012, 84, 6378-6385.

35 van der Veen, M.A. Vermoortele, F., De Vos, D.E., Verbiest, T., Anal. Chem., 2012, 84, 6386-6390.

36 Vancleuvenbergen, S.; Hennrich, G.; Willot, P.; Koeckelberghs, G.; Clays, K.; Verbiest, T., van der Veen, M.A., J. Phys. Chem. C 2012, 116, 12219-12225.

37 Serra-Crespo, P.; van der Veen, M.A.; Gobechiya, E.; Houthoofd, K.; Filinchuk, Y.; Kirschhock, C.E.A.; Martens, J.A.; Sels, B.F.; De Vos, D.E.; Kapteijn, F.; Gascon, J., J. Am. Chem. Soc. 2012, 134, 8314-8317.

38 Volkringer, C.; Loiseau, T.; Haouas, M.; Taulelle, F.; Popov, D.; Burghammer, M.; Riekel, C.; Zlotea, C.; Cuevas, F.;
Latroche, M.; Phanon, D.; Knöfelv, C.; Llewellyn, P. L.; Férey, G.; Chem. Mater. 2009, 21, 5783-5791.

39 Ibarra, I. A.; Yang, S.; Lin, X.; Blake, A. J.; Rizkallah, P. J.; Nowell, H.; Allan, D. R.; Champness, N. R.; Hubberstey, P.; Schröder, M.; Chem. Commun. 2011, 47, 8304-8306.

40 Reinsch, H.; Krüger, M.; Wack, J.; Senker, J.; Salles, F.; Maurin, G.; Stock, N.; Micropor. Mesopor. Mater. 2012, 157, $50-55$.

41 Lacroix, P.G.; Eur. J. Inorg. Chem. 2001, 339-348.

42 Verbiest, T., Houbrechts, S., Kauranen, M., Clays, K., Persoons, A.; J. Mater. Chem. 1997, 7, 2175.

43 van der Veen, M.A.; Verbiest, T.; De Vos D.E., Micropor. Mesopor. Mater. 2012, DOI: 10.1016/j.micromeso.2012.04.051.

44 Evans, O.R., Lin, W; Chem. Rev. 2012, 112, 1084-1104.

45 Serra-Crespo, P.; Gobechiya, E.; Ramos-Fernandez, E. V.; Juan-Alcañiz, J.; Martinez-Joaristi, A.; Stavitski, E.; Kirschhock, C. E. A.; Martens, J. A.; Kapteijn, F.; Gascon, J.; Langmuir 2012, 35, 12916-12922. 
TOC-graphic

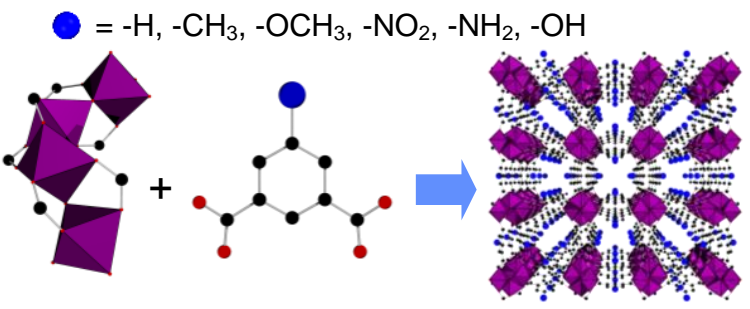

non-centrosymmetry induced by functional groups 